1,175 horse-power. A previous edition of this machine, the Messerschmitt Bf 109, with an engine of 950 horse-power, is credited with a maximum speed of 315 miles an hour, and this performance is about what might be expected for this class of fighter aeroplane with its necessary equipment. The great increase in speed of the new machine with so small an increase in rated power suggests that the term 'fighter' is a misnomer, and that the machine, while its design may be based on such a class, is almost certainly a specially fitted one which would be impracticable for the carrying of standard military equipment. Also the engine must have been giving considerably more than its rated power, which suggests that it was running under conditions that could not have been maintained in practical service work. Although this does not mean that the German Air Force now possesses a single-seater fighter of such a performance, the setting up of the record is an achievement upon which the German aircraft industry is to be deservedly congratulated.

\section{Engineering Research at the City and Guilds College}

A SHORT general account has been issued by the City and Guilds College, Imperial College of Science and Technology, of researches in progress at the College which are mainly financed by an annual grant of the Clothworkers Company given to further engineering research. This research report for 1937-38 contains a brief account of the fluid motion research in the Department of Aeronautics. In the Department of Civil Engineering experimental work on the static loading of a 10-ft. span voussoir arch has been completed which has shown that the generally accepted method of design is unduly pessimistic since even lime mortar joints can resist some tensile stress, and with cement mortar the first sign of failure is at a considerably higher load than that given by the classical theory. An investigation of stresses in suspension bridges is in progress, and in addition to various structural researches the problems of river meander, tidal phenomena, wave research and tests of bituminous jointing compounds for liquid-retaining concrete structures have received attention in the Department. The Department of Electrical Engineering has constructed a high-frequency Wheatstone bridge and also a high-frequency Schering bridge. Besides its work on heat transmission, the Department of Mechanical Engineering has been responsible for work on heat dissipation from surfaces by natural convection in gases and liquids, including mercury, on heat transfer from gases flowing through packed solids, radiation from non-luminous gases, convection in pipes at low velocities, evaporation and convection, gumming tests on lubricating oils with the HelmoreGriffiths oil-testing machine, the mechanical properties of metals near their melting-point and on internal combustion engines.

\section{Post-graduate Studies in the University of Bombay}

Twe Deccan College, which was abolished some years ago, is apparently to be revived by the Government of Bombay as an institution for post-graduate work in arts. The scheme has given occasion to a candid friend of higher education in India in general and the University of Bombay in particular to direct attention in an article recently published in the Mahratta to some of its shortcomings, and to make suggestions for ensuring that they do not vitiate the work of the proposed Deccan College Institute. The existent provision for post-graduate instruction in the University is described as farcical and the standards of undergraduate work in India generally, and particularly in Bombay, as so low that the attainments of a B.A. or B.Sc. are, more often than not, at or below the level of a good freshman in a British university. "Research" or "direction of research" is too often a pretext for shirking genuine work, and much nonsense is talked about the evils of "overlecturing" and "spoon-feeding". What is wrong with higher studies is a deficiency of strenuous, orderly, conscientious, healthily motivated work under competent direction and close supervision. It is suggested that the new Institute should make good the deficiency so far as possible by putting graduates through a discipline which they ought to have already experienced, including the regular and frequent submission of written work and its patient examination by instructors intent on eliminating the indolent and incapable. The proposed fields of study are mathematics, philosophy, English, philology, Indian languages, history and economics. In view of the growth of unemployment among the educated classes and the evils attendant on the existence of an unemployed and unemployable university proletariat the comment suggests itself: higher education forwhat?

\section{The Geographical Laboratory}

A USEFUL pamphlet by Prof. Griffith Taylor, entitled "The Geographical Laboratory" (University of Toronto Press, 1938), sketches with a varying amount of detail a three years course in geography for North American universities. Much of it, however, would be equally applicable to students in Europe, and there should be no difficulty in adapting the more special American section to other requirements. The course is carefully graded, leading from map reading, simple surveying and standard projections to the treatment of statistics, the study of graphs and correlation coefficients and problems of navigation. The matter for the allied lecture courses is also indicated. The courses express an ideal which in their comprehensiveness might be difficult of fulfilment, but the pamphlet should certainly prove a useful guide to both teachers and students.

\section{Conference on Photography}

THE Manchester and District Branch of the Institute of Physics is arranging to hold a conference on "Photography" on July 3-4 in the Physics Department, the University, Manchester. The meetings will begin at 2.30 p.m. on the first day and will terminate at 4.0 p.m. on the second day; they are open without formality of any kind to non-members as well as to members of the Institute of Physics. The events 